\title{
SURGICAL OPTIONS FOR NEOPLASTIC LARGE BOWEL OBSTRUCTION
}

\author{
Madjov R., P. Arnaudov, I. Plachkov, V. Bojkov, P. Chernopolsky \\ University Hospital "St. Marina", Medical University - Varna
}

Reviewed by: assoc. prof. R. Radev

\section{SUMMARY}

Colorectal cancer is the third most common cancer in men and the second in women worldwide. The majority of the cases of acute neoplastic large bowel obstruction are secondary to colorectal cancer. The other reasons are those from ovarian cancer, bladder cancer, metastatic pelvic cancer, lymphoma, sarcoma. Surgery is the cornerstone of CRC cancer treatment and is generally undertaken within 6-8 months of diagnosis. The vast majority of colon cancers can be resected with curative intent. As a result hundreds of thousands of people with resected CRC are candidates for surveillance. As a whole patients with malignant colonic obstruction carry greater risk of poor outcome from the therapeutic procedures and they have shorter surveillance and survival rate, compared with those without complicated course of CRC. Therapeutic strategy in patients with neoplastic large bowel obstruction is mainly determined by location of the obstruction, clinical stage and performance status. Therapeutic strategy in those patients could one of the most challenging clinical scenaria, balansing between advantages/benefits and disadvantages of surgical interventions and procedures, there prognosis and outcome, tumor biology and last but not least, the quality of life of the patients.

Key words: colorectal cancer, neoplastic colonic obstruction, Hartmann's procedure, one-stage resection, endoluminal stenting

Colorectal cancer (CRC) is the third most common cancer in men (663 000 cases, $10 \%$ of the total) and the second in women (570 000 cases, $9,4 \%$ of the total) worldwide. Almost $60 \%$ of the cases occur in developed regions. Incidence rates are substantially higher in men than in women (overall sex ratio of the ASRs 1,4:1,0).

About 608000 deaths from CRC are estimated worldwide, accounting for $8 \%$ of cancer deaths, making it the fourth most common cause of death from cancer. CRC is the second leading cause for cancer death in the western countries and USA (over 50000 deaths annually). Every year approximately 222620 new cases of CRC are diagnosed in 15 of the countries from European union (GLOBOCAN 2000). These are quite serious data and facts, which underscores not only the medical importance, but also social and economic significance of this cancer localization. The incidence of colonic cancer thereby supersedes rectal cancer by one third.

The majority of the cases of acute malignant colonic obstruction are secondary to colorectal cancer. The other reasons for malignant colonic obstructions are those from ovarial cancer, bladder cancer, metastatic pelvic cancer, lymphoma, sarcoma. Breast cancer and melanoma (fig. 1)

Address for correspondence:

R. Madjov, Second Department of Surgery, University Hospital "St. Marina", $1^{\text {st }}$ Hr. Smirnensky blvd., Varna-9010

e-mail: rmadjov@mail.bg are the most common extra gastrointestinal tract diseases as causes ca for acute malignant intestinal obstruction.

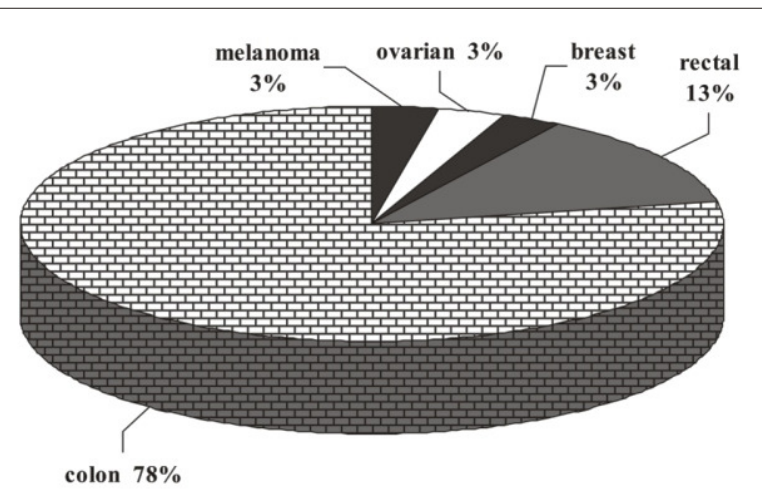

Fig.1. Most common reasons for neoplastic colonic obstruction

Surgery is the cornerstone of CRC cancer treatment and is generally undertaken within 6-8 months of diagnosis. The vast majority of colon cancers, i.e. about $85-90 \%$ can be resected with curative intent. As a result hundreds of thousands of people with resected CRC are candidates for surveillance.

The prognosis in patients with CRC depends from several factors but most of all from the stage at the time of diagnosis. Approximately $55-60 \%$ of all patients are admitted in the surgical departments with advanced CRC (stage III or 
IV). About $30 \%$ of the patients with CRC already have metastases at the time of initial diagnosis of the disease.

Between 15-20\% of the patients with colonic cancer present with clinical symptoms of acute obstruction ( 8 to $29 \%$ from all cases according to literature review). Almost $\mathbf{8 5 \%}$ of the patients suggested for emergency surgical colorectal interventions are those with obstructive CRC.

The most common complications of CRC are:

- Bowel obstruction (small intestine and large bowel).

- Perforation.

- Obstruction + perforation.

- Massive bleeding.

Neoplastic large bowel obstructions are still a challenging problem for surgeons, gastroenterologists, endoscopists. Emergency surgery for acute colonic obstruction carries a significant risk of mortality and postoperative morbidity and a large number of patients will have a colostomy which is either temporary or permanent.

Obstruction is most commonly found in the left colon. The higher risk is in the site of the flexura coli lienalis - almost $\mathbf{5 0} \%$ of the tumors with this location cause obstruction. The other locations in the left colon manifest with obstruction approximately in $\mathbf{2 5 \%}$ (fig. 2).

Perforation of the colon additionally leads to severe complications in patients with obstructive CRC - found in $\mathbf{7 - 1 1 \%}$ of the cases. Malignant colonic obstruction is diagnosed more commonly in the advanced aged patients and females.

The tumor leads to obstruction in different ways - intramural, intraluminal, and extramural (probably the most common way in patients with advanced cancer disease).

376 patients admitted in the clinic (for 12 year period) with malignant bowel obstruction were reviewed; mean age 64,6 (varied between 23 - 97 years). Primary neoplasm of the bowel was found in $84 \%$ of the patients. Other reasons were: recurrence - $13,6 \%$ in our cases; metastases; ovarian cancer; retroperitoneal tumor.

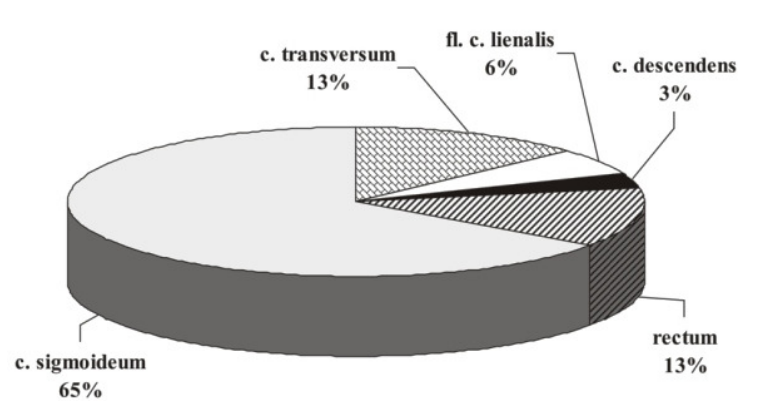

Fig. 2. Most common location sites of malignant colonic obstruction

According to the anamnesis at the time of admission of the patients in the surgical department duration of the clinical manifestation varies, but almost half of them had signs and symptoms from 3 days (54,5\%), 4 - 6 days - 24,8\%, but in $20,7 \%$ - duration of there complaints is more than 7 days. At the time of admission in hospital patients with malignant colonic obstruction complain from abdominal cramps or/and abdominal pain (80 - 85\%) and episodes of nausea and vomiting (65\%), change in bowel habits - found in $2 / 3$ of the patients. During physical examination most common findings were: distension (80-83\%), abdominal pain, tenderness in palpation (44-48\%), altered bowel sounds, rarely palpable rectal mass $(3-4 \%)$.

Perforation associated with obstruction was found in $14 \%$ of our patients $(67 \%$ at the site of the obstructive neoplasm). Peritonitis was found in 59 patients.

\section{Diagnostic strategy must include:}

- Plain abdominal X-Ray films for signs of intestinal obstruction.

- Preoperative ultrasonography.

- CT scans (gives information about the localization of the tumor, size, and also about the spread of the disease - local invasion and distal metastases).

- Fibrocolonoscopy (sigmoscopy) - offers possibility for histological verification and endoscopic manipulations, which if successful, can assure bridge to the surgical intervention lately, after careful medication of the patients.

As a whole patients with malignant colonic obstruction carry greater risk of poor outcome from the therapeutic procedures and they have shorter surveillance and survival rate, compared with those without complicated course of CRC. Barillari et al. found that 5-year survival rate in patients with obstructive CRC is $35,8 \%$ in comparison with $55,5 \%$ in patients with elective surgery and lack of obstruction.

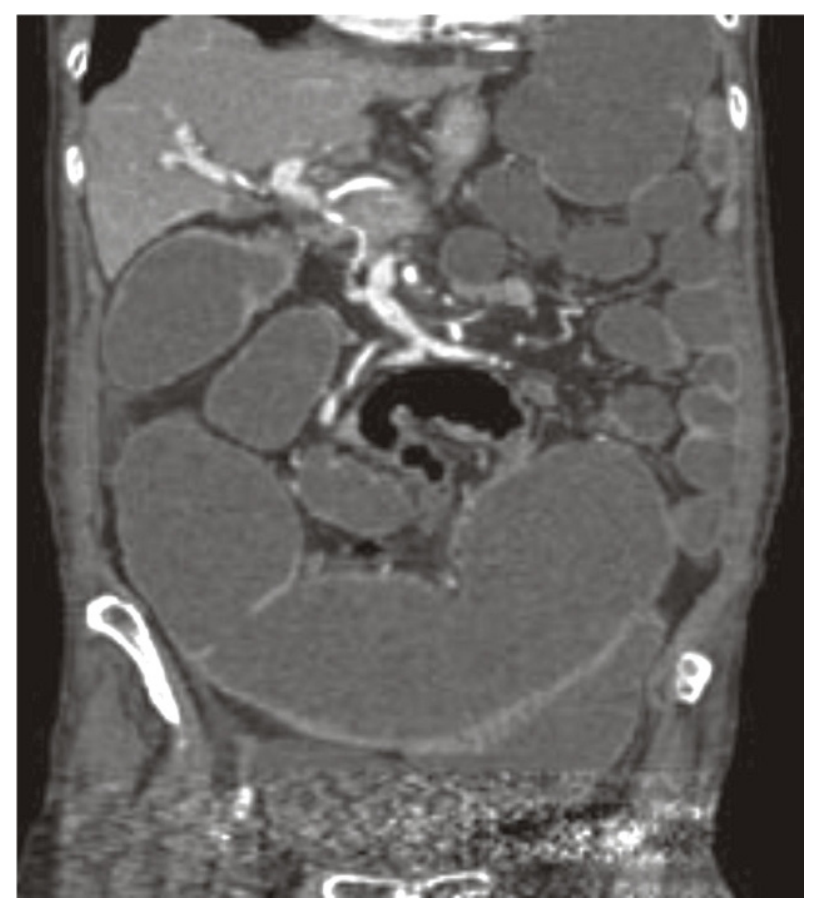

Fig. 3. CT scan - obstructing CRC

Therapeutic strategy in patients with malignant large bowel obstruction is mainly determined by: 


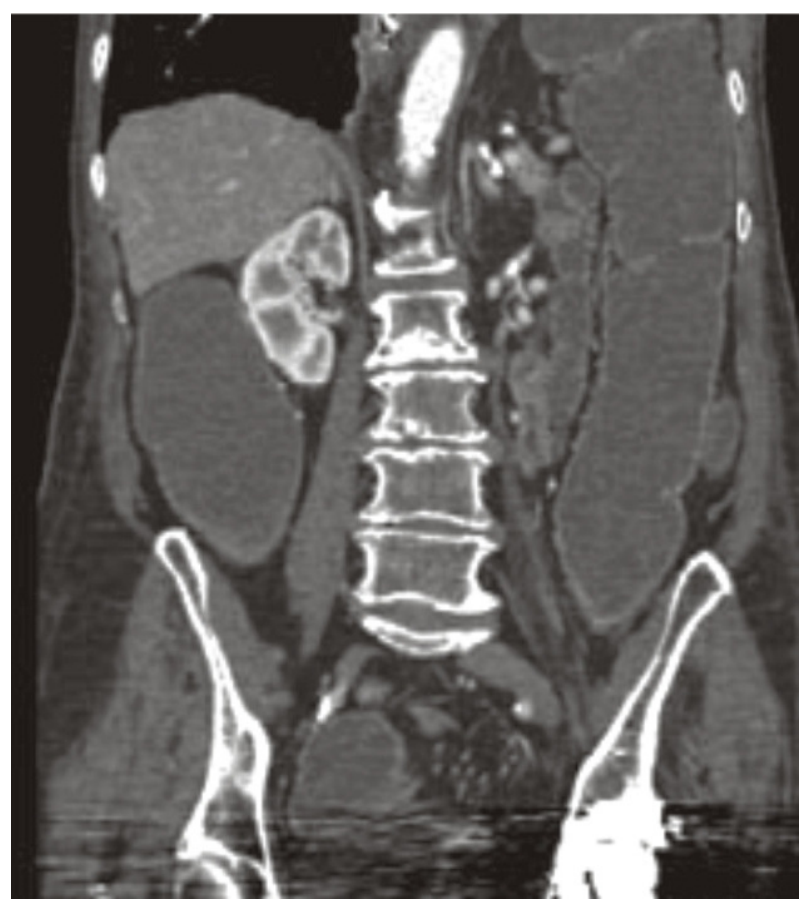

Fig. 4. CT scan - obstructing sigmoid cancer

- Location of the obstruction (right-sided, left-sided, upper rectum, lower rectum).

- Clinical stage of the disease (which correlates strictly with the prognosis).
- General condition of the patient (performance status) severe comorbid diseases - cardio-vascular, pleuro-pulmonary, diabetes

- Previous chemotherapy.

Therapeutic strategy in those patients could one of the most challenging clinical scenaria, balansing between advantages/benefits and disadvantages of surgical interventions and procedures, there prognosis and outcome, tumor biology and last but not least, the quality of life of the patients.

\section{Therapeutic options in patients with malignant colonic obstructions varied between:}

- Radical resection with one-stage anastomosis (with or without intra-operative colonic irrigation).

- Subtotal colectomy with one-stage anastomosis.

- Hartmann's procedure (two-stage operation).

- Three-stage operation (stoma, resection and anastomosis, closure of the stoma).

- Colostomy / Ileostomy.

- Coecostomy.

- By-pass anastomosis (internal derivation, by-pass without resection of the tumor).

- Nd: YAG laser photoablation.

- Endo-luminal stenting.

Patients with malignant colonic obstruction are characterized with higher operative morbidity and postoperative hospital mortality in comparison with those with elective surgery and resection of non-obstructive CRC. That is why it is mandatory careful preoperative stratification of the pa-

Table 1. Therapeutic options in neoplastic colonic obstruction*

\begin{tabular}{||l|l|l|l|}
\hline \hline Procedure & Indications & Advantages & Possible problems \\
\hline Colostomy Coecostomy & $\begin{array}{l}\text { Palliation in high risk pts. } \\
\text { Minimally invasive. }\end{array}$ & $\begin{array}{l}\text { The only option if stenting is not } \\
\text { possible. }\end{array}$ & Burden of every colostomy \\
\hline Endo-lumunal stenting & $\begin{array}{l}\text { Palliation in high risk pts. } \\
\text { Used as "bridge to surgery" }\end{array}$ & $\begin{array}{l}\text { Lower mortality rate. } \\
\text { Less colostomies. }\end{array}$ & $\begin{array}{l}\text { Not always successful. } \\
\text { Very expensive stents. } \\
\text { Limited experienced centers. } \\
\text { Long-term results are uncertain. }\end{array}$ \\
\hline Hartmann's procedure & $\begin{array}{l}\text { High-risk patients } \\
\text { Surgical team without enough } \\
\text { experience in colorectal surgery. }\end{array}$ & $\begin{array}{l}\text { Effective both for tumor and } \\
\text { Nostruction. } \\
\text { insufficiency of anastomosis. }\end{array}$ & $\begin{array}{l}\text { Second procedure needed for } \\
\text { reconstruction of GI tract } \\
\text { continuity. }\end{array}$ \\
\hline $\begin{array}{l}\text { Resection with one-stage } \\
\text { anastomosis }\end{array}$ & $\begin{array}{l}\text { Patients with acceptable } \\
\text { operative risks. }\end{array}$ & $\begin{array}{l}\text { No need for colostomy. Effective } \\
\text { both for tumor and obstruction. }\end{array}$ & $\begin{array}{l}\text { Insufficiency of anastomosis and } \\
\text { postoperative leakage. }\end{array}$ \\
\hline $\begin{array}{l}\text { Intraoperative colonic } \\
\text { irrigation }\end{array}$ & $\begin{array}{l}\text { In combination with one-stage } \\
\text { anastomosis. }\end{array}$ & $\begin{array}{l}\text { Need for well done bowel } \\
\text { preparation. }\end{array}$ & $\begin{array}{l}\text { Operative time consuming. } \\
\text { Lack of proved benefits. }\end{array}$ \\
\hline Subtotal colectomy & $\begin{array}{l}\text { Intraoperative evidence for } \\
\text { proximal bowel damages or } \\
\text { synchronous tumors. }\end{array}$ & $\begin{array}{l}\text { Safety procedure if done by an an } \\
\text { experienced surgeon. }\end{array}$ & $\begin{array}{l}\text { Longer procedure than segmental } \\
\text { resection. Postoperative diarrhea. }\end{array}$ \\
\hline \hline
\end{tabular}

* adapted by V.Trompetas / Ann R Coll Surg Engl 2008; 90:181-186 
tients according to risk factors and individualized approach in every case with obstructive CRC.

According to the authors from the Association of Coloproctology of Great Britain and Ireland the most important predictive factors are: age, ASA grade, stages of the disease and emergency surgery. Emergency surgical intervention carried for malignant colonic obstruction is characterized with significant risk for high postoperative morbidity and mortality. Besides colostomy is performed in quite a serious percentage of the patients, which could be temporary or even permanent. Several retrospective multicenter studies (including one-, twoor three-staged procedures) found that postoperative mortality rate varies between $12-38 \%$, and complications were found in $11-60 \%$ in patients with malignant bowel obstruction. Also CRCs causing obstruction correlate with high local recurrence rate.

\section{Colostomy (coecostomy) and Nd: YAG laser photoablation}

Mainly palliative therapy in patients with nonresectable rectosigmoid cancer, severely locally advanced tumor process, lots of metastases or in patients with extremely high operative risk.

Simple colostomy could be a part (first stage) of the staged management for malignant colonic obstruction. The second stage is performed few weeks later - then the tumor is resected radically, anastomosis is performed and colostomy is closed during the same operation or at a third stage.

Colostomy is the only option in departments where stenting is not possible.

The advantages of stoma formation is that it provides decompression of the dilated bowel, reduces the risk of surgical trauma. Nowadays staged procedures for left-sided malignant colonic obstruction are no longer used in the leading surgical departments. De Salvo et al. /2004/ performed a review comparing primary or staged resection and found no evidence suggesting a benefit in postoperative morbidity and mortality with either strategy.

$\mathrm{Nd}$ : YAG laser photoablation is proved to be effective for successful management of bleeding and relieve of the obstructive symptoms in patients with recto-sigmoid localization of the cancer.

\section{Endo-luminal stenting}

Colonic stents were introduced in the 90s and were used mainly for:

- Palliation in patients with non-resectable obstructive CRC or patients not suitable for emergency surgery (extremely high-risk patients).

- As a "bridge to surgery" - they are used in emergency conditions in patients with obstructive CRC in order to relieve the obstruction. After that the patient is treated medicamentously, carefully prepared, recovers from the obstruction, properly staged concerning $\mathrm{CRC}$ and if possible elective surgery is performed in the second stage.

The colonic stents could be placed under fluoroscopic or endoscopic control (preferred by more authors in special- ized centers). Technical success from the procedure reaches up to $92 \%$, while clinical success (total relief of the obstruction) is up to $88 \%$.

The problems related to endo-luminal stenting and complications after the procedure are: perforation of the bowel $3,5-3,7 \%$ of the cases, re-obstruction $-7 \%$ and migration of the stent $-10-12 \%$. Mortality rate according to literature review is $0,5-0,6 \%$.

\section{Staged operative procedures}

Historically for the treatment of neoplastic colonic obstruction was considered that the best approach was with a three-stage procedure:

- Divert. Colostomy for relief of the bowel obstruction.

- Followed by resection and anastomosis, but stoma was left in order to protect the anastomosis.

- Reverse stoma at a third stage.

This approach was superseded by a two-stage procedure such as Hartmann's operation (resect without anastomosis; restore continuity later).

More recently the concept of resection, on-table lavage to empty the resected colon of stool and primary re-anastomosis has been proposed to avoid a stoma and second operation.

Theoretically two- and three-staged procedures suggest for reducing the percentage of postoperative complications and better postoperative results. Sjodahl et al.(2003) in a large retrospective study in patients with obstructive CRC found that the complications and mortality rate in two groups (one with primary resection and anastomosis and the other with staged resection) were $15 \%$ against $25 \%$ postoperative morbidity and $10 \%$ against $15 \%$ mortality rate. The additional morbidity and mortality rate in the staged procedures was closely connected with the formation, подържането and closure of the stoma. Even the procedure for reverse of the stoma at a third stage carries risk for complications varying from $20 \%$ to $37 \%$. Besides in about $25-40 \%$ of the patients restoring the continuity of the gastrointestinal tract is not performed (stoma is not reversed) because of high operative risk and/or refusal of the patients for another operation.

Staged procedures nowadays are used quite rarely mainly because of the high percentage of complications and postoperative hospital mortality, prolonged hospitalization and need for multiple interventions, which finally leads to higher hospital costs.

\section{Primary radical resection}

Primary colonic resection is considered for standard procedure by most of the leading colorectal surgeons. The main controversy in the management of obstructing colon cancers is the operative approach to those in the left and sigmoid colon. Debates are about the type of the operative procedure.

Primary resection with formation of proximal colostomy (Hartmann's procedure) is considered to be the safest option. Main advantages of this operation are that there is no risk of insufficience of the anastomosis (postoperative leak- 
age) and this kind of procedure could be done by less experienced surgical team. Disadvantages include: need of second big operation, reconstruction of gastro-intestinal continuity and last but not least the fact that in about 40 to $60 \%$ of the patients such operation is not performed, which leads to impaired quality of life.

Primary radical resection and anastomosis (one-stage operation) has the benefits, of being a definitive procedure according both to the tumor and bowel obstruction and there is no need of following procedures. The main disadvantages include the risk of insufficiency of the anastomosis and need of experienced, highly qualified surgeon. These operations should be performed in specialized centers in order to optimize the results.

Nowadays two are the main one-staged procedures used in colo-proctology - segmental resection and subtotal colectomy. In a large retrospective study concerning patients with one-stage operation surgeons from the University of Minnesota found that subtotal colectomy was performed in $32 \%$, and segmental resection was done in $68 \%$ of the patients with obstructive CRC. There were no significant differencies concerning postoperative morbidity $(11 \%)$ and postoperative mortality $(12,5 \%)$ between two groups. Subtotal colectomy was performed in cases when there were lesions in the proximal parts of the bowel (lacerations, perforations...) and/or synchronous tumors found intra-operatively.

Operative procedures performed in our patients with malignant bowel obstruction were:

- Curative resection - $74,8 \%$

- Extended bowel resection - 24,0\%

- Conservatively treated - 32 pts. (followed by elective surgery in 24).

Palliative procedures were performed in $25,2 \%$ of the patients with neoplastic bowel obstruction. They included either tumor resection or decompressive stoma (ileo-; coecotransverse- or sigmostomy) and were done in patients with distant metastases or locally advanced cancer.

\section{Postoperative morbidity and mortality:}

After elective surgery the complications are found in about $20 \%$ of the patients, while after emergency surgery this percentage goes up and reaches $36-39 \%$. The most common surgical complications were wound infections $(6,6 \%)$, while from non-surgical complications most common were cardio-pulmonary $(5,1 \%)$ and renal complications $(5,8 \%)$. Population studies have shown that $25 \%$ of all postoperative deaths after surgery for bowel cancer occur in patients who present with malignant bowel obstruction. Total postoperative mortality rate in patients with colo-rectal cancer according to literature review for the last two decades is $4,9 \%$. But there is a strong differentiation between the elective surgery patients (mortality - 3,5\%; varied between 0 to $8,0 \%)$ and patients with emergency surgical interventions (mortality - 9,5\%; varied between $2 \%$ and $21 \%$ ).

Overall morbidity rate in our patients was $26,9 \%$. Postoperative mortality was $5,6 \%$, but patients with serious coexist- ing disease had significantly higher incidence of postoperative complications $(41 \%)$ and postoperative death $(33 \%)$. Additional risk factors, influencing significantly over the postoperative complications and mortality rate were: severe comorbidity, age of the patient (over $70 \mathrm{yrs}-7,4 \%$ ), surgical approach (radical resection, by pass anastomosis...). Lowest mortality rate is calculated in elective surgery and lack of comorbidity - 2,3\%. In cases of emergency surgery greatest importance for the outcome had severe comorbidity:

- lack of comorbidity - $4,8 \%$ mortality rate;

- one comorbid disease - $15 \%$ mortality rate;

- more than one comorbid disease - $28 \%$ mortality rate.

\section{CONCLUSIONS}

- Neoplastic colonic obstruction requires emergency surgical management with curative intention in order to eliminate all the possible complications. Primary neoplasms are usually removable in cases of malignant bowel obstructions.

- Every case of obstructive CRC requires careful assessment and individualized approach. Advanced age, complete obstruction, coexisting diseases and requirement for extended bowel resections are not contraindications for emergency surgical treatment aimed to relieve the symptoms.

- Mostly the location of the neoplasm and general condition of the patient determines the surgical strategy. All patients should undergo fluid resuscitation for correction of the electrolyte disturbances and optimization of the performance status before operative procedure.

- Radical resection and primary anastomosis is a procedure of choice for patients with malignant colonic obstruction and absence of generalized peritonitis, good performance status of the patient and acceptable morbidity and mortality risk.

- Subtotal colectomy should be considered in those patients, when malignant bowel obstruction is complicated with perforation of the coecum, synchronous lesions or signs of colonic ischemia.

- Hartmann's procedure should be performed only in patients with high operative risk.

- Endo-luminal stenting could be performed either as palliation or as a "bridge" to elective surgery.

- Simple colostomy/coecostomy should be reserved only for those patients with extremely high operative risk, poor general condition and there is no possibility for placement of colonic stents.

- Factors other than disease that may impair survival in CRC are: perforation, obstruction, poor differentiation, mucinous/signet ring histology, lympho-vascular invasion, perineural invasion, DNA aneuploidy, elevation of CEA. 
- Ethical principles related to medical and surgical treatment in patients with advanced CRC can be considered under the following headings:

- Beneficence / do good /

- Non maleficence / do not harm/

- Autonomy / respect the rights of the individual patient /

\section{REFERENCES}

1. Adenis A, Conroy T, Lasser P, et al: Standards, Options and Recommendations: Carcinoma of the colon. Electronic Journal of Oncology 2001;1:83-89

2. Anthony T, Simmang C, Hyman N, et al: Practice parameters for the surveillance and follow-up of patients with colon and rectal cancer. Dis Colon Rectum 47:807-817, 2004 Colorectal Cancer Surveillance Guideline www.jco.org 8519

3. Association of Coloproctology of Great Britain and Ireland. Guidelines for the Management of Colorectal Cancer. London: Association of Coloproctology of Great Britain and Ireland, 2007.

4. Borowski DW, Kelly SB, Bradburn DM, et al. Impact of surgeon volume and spe-cialization on short-term outcomes in colorectal cancer surgery. $\mathrm{Br} \mathrm{J}$ Surg 2007;94:880-9.

5. Cancer Research UK. Bowel cancer statistics. 2009. http://info.cancerresearchuk.org/cancerstats/types/bo wel/index.htm?script?true (accessed June 2010).

6. Coleman MP, Quaresma M, Berrino F, et al. Cancer survival in five continents: a worldwide population-based study (CONCORD). Lancet Oncol 2008;9:730-56.

7. Finan P, Smith JJ, Morris E, et al. National Bowel Cancer Audit, 2009. Leeds: The NHS Information Centre, 2009.

8. Nelson H, Petrelli N, Carlin A, et al. Guidelines 2000 for colon and rectal cancer surgery. J Natl Cancer Inst 2001;93:583-96.

9. Glimelius B, Pahlman L, Cervantes A, et al. Rectal cancer: ESMO clinical practice guidelines for diagnosis, treatment and follow-up. Ann Oncol 2010;21(Suppl 5):v82-6.

10. Minsky BD, Guillem JG. Multidisciplinary management of resectable rectal cancer: new developments and controversies. Oncology (Williston Park) 2008;22:1430-1437.

11. Sprangers MAG, Taal BG, Aaronson NK, et al. Quality of life in colorectal cancer: stoma vs. nonstoma patients. Dis Colon Rectum 1995;38:361-369.

12. Au HJ, Mulder KE, Fields AL. Systematic review of management of colorectal cancer in elderly patients. Clin Colorectal Cancer. 2003;3:165-171.

13. Jemal A, Siegel R, Ward E, et al. Cancer statistics, 2006. CA Cancer J Clin. 2006;56:106 -130.

14. Colorectal Cancer Collaborative Group. Surgery for colorectal cancer in elderly patients: a systematic review. Lancet. 2000;356:968 -974.

15. Clark AJ, Stockton D, Elder A, et al. Assessment of outcomes after colorectal cancer resection in the elderly as a rationale for screening and early detection. Br J Surg. 2004;91:1345-1351.

16. Townsley C, Pond GR, Peloza B, et al. Analysis of treatment practices for elderly cancer patients in Ontario, Canada. J Clin Oncol. 2005;23:3802-3810.

17. Engstrom PF, Benson AB 3rd, Chen YJ, et a1. Rectal cancer clinical practice guidelines in oncology. J Natl Compr Canc Netw. 2005;3:492-508.

18. NHS Connecting for Health. OPCS Classification of Interventions and Procedures Version 4.5. Volume I Tabular index. London: The Stationery Office, 2009.

19. NHS Connecting for Health. OPCS Classification of Interventions and Procedures Version 4.5. Volume II - Alphabetical index. London: The Stationery Office, 2009.

20. Tekkis PP, Poloniecki JD, Thompson MR, et al. Operative mortality in colorectal cancer: prospective national study. BMJ 2003;327:1196-201.

21. Sjo OH, Larsen S, Lunde OC, et al. Short term outcome after emergency and elective surgery for colon cancer. Colorectal Dis 2008;11:733-9.

22. Morris EJ, Jordan C, Thomas JD, et al. Comparison of treatment and outcome information between a clinical trial and the National Cancer Data Repository. Br J Surg 2011;98:299-307.

23. Nelson H, Petrelli N, Carlin A, et al. Guidelines 2000 for colon and rectal cancer surgery. J Natl Cancer Inst 2001;93:583-96.

24. Chandler PJ, Orkin BA. Rectal carcinoma: operative treatment. In: Beck DE, Wexner SD, editors. Fundamentals of anorectal surgery. $2^{\text {nd }}$ ed. London (U.K.): Saunders Co.; 1998. p. 301-67.

25. Zaheer S, Pemberton JH, Farouk R, Dozois RR, Wolff BG, Ilstrup D. Surgical treatment of adenocarcinoma of the rectum. Ann Surg 1998;227:800-11.

26. Compton CC, Fielding LP, Burgart LJ, Conley B, Cooper HS, Hamilton SR, et al. Prognostic factors in colorectal cancer. College of American Pathologists Consensus Statement 1999. Arch Pathol Lab Med 2000;124:979-94.

27. Eldar S, Kemeny MM, Terz JJ. Extended resections for carcinoma of the colon and rectum. Surg Gynecol Obstet 1985;161:319-22.

28. Eisenberg SB, Kraybill WG, Lopez MJ. Long-term results of surgical resection of locally advanced colorectal carcinoma. Surgery 1990; 108:779-85; discussion 785-6.

29. Clinical Outcomes of Surgical Therapy Study Group. A comparison of laparo-scopically assisted and open colectomy for colon cancer. $N$ Engl J Med 2004; 350:2050-9

30. Phillips RK, Hittinger R, Fry JS, Fielding LP Malignant large bowel obstruction. Br J Surg 1985; 72:296-302

31. Serpell JW, McDermott FT, Katrivessis H, Hughes ESR. Obstructing carcinomas of the colon. $\mathrm{Br}$ $J$ Surg 1989; 76:965-969

32. Meyer F, Marusch F, Coch A, et al. and the German Study Group 'Colorectal Carcinoma (Primary Tumor). Emergency operation in carcinoma of the left colon: value of Hartmann's procedure. Tech Coloproctol 2004; 8:S226-229 
33. Kronborg O. Acute obstruction from tumor in the left colon without spread. A randomized trial of emergency colostomy versus resection. Int J Colorectal Dis 1995; 10:1-5

34. De Salvo GL, Gava C, Lise M, Pucciarelli S. Curative surgery for obstruction from primary left colorectal carcinoma: Primary or staged resection? Cochrane database Syst Rev 2004; 2:CD002101

35. Zorcolo L, Covotta L, Carlomagno N, Bartolo DC. Safety of primary anastomosis in emergency colo-rectal surgery. Colorectal Dis 2003; 5:262-269

36. Villar JM, Martinez AP, Villegas MT, et a1. Surgical options for malignant left-sided colonic obstruction. Surg Today 2005; 35:275-281
37. Goyal A, Schein M. Current practices in left-sided colonic emergencies. A survey of US gastrointestinal surgeons. Dig Surg 2001; 18:399-402

38. Harris GJC, Senagore AJ, Lavery IC, Fazio $\mathrm{VW}$. The management of neoplastic colorectal obstruction with colonic endoluminal stenting devices. Am J Surg 2001; 181:499-506

39. Xinopoulos D, Dimitroulopoulos D, Theodosopoulos T, et al. Stenting or stoma creation for patients with inoperable malignant colonic obstruction? Surg Endosc 2004; 18:421-426

40. van Hooft JE, Fockens P, Marinelli AW, et a1. on behalf of the Dutch Stent-In study group. Premature closure of the Dutch Stent-in I study. Lancet 2006; 368:1573-74 